\title{
Approche anthropologique et sociolinguistique des usages linguistiques et des mixités matrimoniales en Inde
}

Madhura Joshi

\section{CpenEdition Journals}

Édition électronique

URL : http://journals.openedition.org/esp/2841

DOI : $10.4000 /$ esp.2841

ISSN : 2532-0319

Éditeur

Centre d'Information sur l'Éducation Bilingue et Plurilingue

\section{Édition imprimée}

Date de publication : 1 décembre 2013

Pagination : 106-108

ISSN : 1127-266X

\section{Référence électronique}

Madhura Joshi, «Approche anthropologique et sociolinguistique des usages linguistiques et des mixités matrimoniales en Inde », Éducation et sociétés plurilingues [En ligne], 35 | 2013, mis en ligne le 01 février 2020, consulté le 17 février 2021. URL : http://journals.openedition.org/esp/2841; DOI : https://doi.org/10.4000/esp.2841 


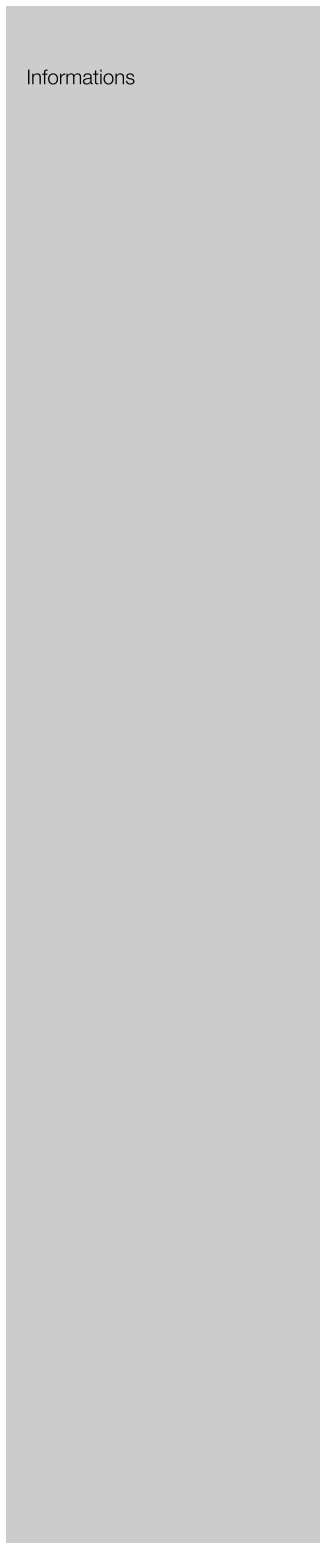

Résumé de thèse

Madhura JOSHI, Approche anthropologique et sociolinguistique des usages linguistiques et des mixités matrimoniales en Inde, Thèse soutenue le 30 novembre 2012 à l'université Paul-Valéry, Montpellier-III, sous la direction de JeanMarie Prieur.

Cette étude conduite pour une thèse de Doctorat en Sciences du langage présente une analyse croisée des discours sur le mariage en Inde et de récits de vie recueillis sur le terrain. Loin de vouloir proposer des descriptions de rites de mariage, l'approche anthropologique est ici investie dans le recueil de données, sous forme d'observations participantes dans des familles. L'approche sociolinguistique permet d'observer la circulation des discours sur l'objet d'étude en privilégiant la parole des sujets sur leur propre mariage.

Le terrain, au sens anthropologique et sociolinguistique du terme, reste une notion marquée par l'investissement subjectif du chercheur/de la chercheuse, malgré l'objectivité visée en sciences sociales. En décidant de faire du terrain «chez soi», l'ignorance de celui/celle qui fait sa recherche se révèle davantage et, dès lors, le «chez soi» devient un terrain à «exploiter».

Qu'entend-on par «mariage» lorsqu'on est en présence d'une hétérogénéité de normes régissant la vie sociale dans un pays qu'on qualifie de «sous-continent»? Étape dans la vie, rite de passage incontournable dans les discours sociaux, le mariage en Inde est d'autant plus capital qu'il remplit une fonction de protection sociale par les réseaux de parenté qu'il génère. L'honneur est aussi une notion attachée à la vie communautaire, qui intervient pour empêcher les unions mixtes, et au nom de laquelle une centaine de personnes sont tuées chaque année pour avoir fait un mariage qui va l'encontre des normes sociales.

En replaçant la notion de mariage dans l'historicité des discours et dans le contexte social et politique actuel, l'on perçoit l'acception devenue courante du mariage comme «don de la fille». Une des interrogations soulevées, et à laquelle il est difficile de répondre, c'est de savoir comment du «don» facilitant l'échange entre les hommes, les filles deviennent une «dette» pour leurs familles. Ge qui éclaire quelques-unes des contradictions entre l'égalité théorique (entre les sexes, entre tous les sujets...) affirmée par exemple, par la Constitution, et les inégalités persistantes dans cette société hautement complexe et fortement hiérarchisée. Les 
communautés ne laissent pas toujours aux individus de «droit de sortie» par la capacité d'agir par eux-mêmes, par exemple lorsqu'ils choisissent un conjoint «non-convenable».

Les mariages mixtes sont souvent des mariages «par choix» (qu'ils soient arrangés ou non par la famille ou les amis) et ont le potentiel de remettre en question l'ordre social. La question de la mixité matrimoniale renvoie à celle des appartenances, à la mise en frontières entre un «nous» et un «non-nous». Si l'appartenance de castes (jati) s'avère important du point de vue «-émique» - c'est-àdire «de l'intérieur» de la société - il faut entendre le terme jati comme un terme générique. En effet jati renvoie à la «naissance» (de la racine «jan-»), ce qui peut désigner, dans les discours et selon les circonstances, aussi bien l'appartenance à une communauté endogame, religieuse, régionale, linguistique, nationale... autant de marqueurs de la mixité matrimoniale. Si les discours normatifs valorisent les mariages endogames (à l'intérieur de la communauté) c'est parce qu'ils sont censés assurer une certaine homogénéité des pratiques coutumières des familles des deux conjoints. Cette question de la similarité des pratiques sociales concerne plus particulièrement les femmes. Car en général, ce sont les épouses qui s'adaptent au mode de vie de leurs bellesfamilles.

Une analyse des annonces matrimoniales et des discours des sujets eux-mêmes met en lumière la préférence pour les pratiques endogames. Néanmoins malgré le poids des discours normatifs, tous les mariages mixtes ne sont pas nécessairement rejetés par les familles. Il s'agit là d'un clivage que l'analyse du discours met en évidence. Les mariages mixtes sont implicitement considérés comme des «mariages d'amour». Cette dernière nomination peut porter aussi bien une valeur péjorative, qu'une revendication d'une capacité à agir. Et les «mariages d'amour» s'opposent implicitement aux mariages arrangés par les familles. L'on peut imaginer ainsi le poids, et le regard (dé-)valorisant que portent des désignations utilisées pour qualifier un mariage. En effet, tous les mariages mixtes ne sont pas des «mariages d'amour». Mais leur caractère déviant par rapport à la norme endogame apparaît dans les discours par l'emploi du qualificatif «mariage comme cela» (ashe lagna en langue marathi).

Une présentation des évolutions historiques et sociales dans le domaine des lois du mariage, ainsi que de revendications régionalistes, depuis 1947 (date de l'indépendance de la colonisation britannique) est proposée dans cette recherche. La comparaison avec le cinéma, souvent évoquée pour parler des mariages mixtes, les 
politiques linguistiques dans les familles mixtes, le choix du nom et du prénom des enfants (et des épouses) sont quelques-uns des thèmes auxquels place est également faite dans les analyses. Enfin, cette étude démontre que malgré tous les discours interdisant la mixité matrimoniale, les familles acceptent bon gré mal gré, ces unions. Sauf dans de très rares cas - dans cette enquête où «l'honneur familial» les en empêche... 